\title{
Wittgenstein vs. Rawls
}

Rupert Read, Norwich

'What the liberal really wants is to bring about change which will not in any way endanger his position' - Stokeley Carmichael.

'Nothing is so difficult as not deceiving oneself' - Ludwig Wittgenstein.

\section{Introduction}

Liberal political philosophy is the dominant political philosophy of our time. Perhaps then it is simply unsurprising that many Wittgensteinians (and especially Americans) are card-carrying liberals. Wittgensteinian thinkers as otherwise diverse for instance as Richard Rorty, ${ }^{1}$ Stanley Cavell and Burt Dreben have explicitly praised Rawlsian liberalism, at length.

Like some other British Wittgensteinians ${ }^{2}$, I disagree. I believe that the good is prior to the right. A conception or family of conceptions of the good must be paramount. Life is moral. It's not good enough to 'do the right thing' in some limited sphere, and otherwise just do (and buy) what(ever) you want. If you live in that way, you are plainly not above reproach, and (more importantly) nor is your society.

I would favour a broadly virtue-ethical approach and an egalitarian moral perfectionism. ${ }^{3}$ Moral perfectionism (following Emerson) is alleg-

${ }^{1}$ Consider also Rorty's key recent Wittgensteinian opponents, my fellow 'new Wittgensteinians' Alice Crary and James Conant. The whole tenor of Conant's critique of Rorty, and the crucial closing sentence of Crary's "Wittgenstein and political philosophy" (in our (2000)), make very clear that Crary and Conant consider themselves to be united with Rorty in his political liberalism, even as they are divided from him over Wittgenstein.

${ }^{2}$ I am thinking here particularly of Nigel Pleasants and Phil Hutchinson.

3 This need not be a contradiction in terms. In my view, a perfectionist project that openly favours some conceptions of the good above others (e.g. that favours 'high' culture) can be perfectly compatible with a truly egalitarian distribution of material goods among an entire population, etc. 
edly what Cavell offers, too. But Cavell is very soft on liberal political philosophy in his most sustained engagement with it, in the pages of Conditions handsome and unhandsome. I submit that Cavell's 'moral perfectionism' is neutered, by his unwillingness to confront liberalism. Cavell wants to recover a non-elitist model of perfectionism, but in fact, by going along as much as he does with Rawls, he both (1) goes along with a model of culture that prioritises consumerism above real culture, and (2) nevertheless preserves an economic elite: made up of those systematically favoured by the difference principle. ${ }^{4}$

Liberalism of course has its attractions as a political philosophy, for followers of Wittgenstein. ${ }^{5}$ Most strikingly, perhaps, in its ringing endorsement of freedom of thought. Wittgensteinians strive above all for mental liberation (aka 'the liberating word'). But what gets called 'economic freedom', and freedom to consume: these are not as attractive, I hope, to a Wittgensteinian. Especially not if they amount, as I shall briefly suggest below, to the freedom to milk other people and to milk the future...

And in any case (though I shall not argue for this here): the 'neutrality' between conceptions of the good promised by contemporary liberalism (especially by Rawls) is in my view a fake. It disguises a deeper nonneutrality, a hidden bias. A deep commitment, in fact, to a quasi-relativistic culture of consumerism.

This is why I seek, in this paper, to set Wittgenstein against Rawls. I will offer in what follows a series of reasons for thinking that Wittgensteinians in particular have no excuse for being Rawlsians. These reasons can in the main be briefly summed up under three headings:

${ }^{4}$ Such as e.g. the class described in the (to my mind) unpleasant scenario via which Rawls first details how the difference principle might play out in his 'just' society, on p.78 of Rawls's (1971).

${ }^{5}$ Similarly, Wittgenstein has his serious attractions, at least superficially for Rawlsian liberals (for those impressed by Rawls's founding assumption, interrogated below, that "Justice is the first virtue of social institutions"). Take for instance the following quotes, from "Philosophy" from the Big Typescript (p.171 and p.181): "THE GOAL [OF PHILOSOPHY]: THE TRANSPARENCY OF ARGUMENTS. JUSTICE." "Our only task is to be just. That is, we must only point out and resolve the injustices of philosophy, and not posit new parties - and creeds." 
- Rawls's taking of justice as the first virtue of social institutions is problematic; he more or less assumes this (whereas Wittgenstein would consider other possibilities), and the content of the assumption is certainly very questionable.

- The heart of Rawlsian thinking is, surprisingly (given Rawls's care to argue for the superiority of his view to Utilitarianism), non-actionguiding. Both the difference principle and the 'just savings' principle are open invitations to bad faith. This is because they are non-genuine contracts which nevertheless in some sense pretend to be as-if contracts. I will draw an analogy with Wittgenstein's anti-'privatelanguage' considerations: which are against the 'idea' of a nonlanguage which nevertheless pretends to be as-if a language.

- I submit, in sum, that Rawlsian thinking (see e.g. the previous point) is fundamentally dishonest. Whereas honesty is the paramount watchword of Wittgenstein's thinking. Honesty is for Wittgenstein the first virtue of philosophy...

\section{Harvard Wittgensteins}

Let us begin with a tale of two Wittgensteins: Cavell's and Dreben's...

There have been two great contrasting 'strands' of Wittgensteinianism in and from Harvard, and according to some these are even the two great strands of Wittgensteinianism of our time: Burt Dreben's and Stanley Cavell's. ${ }^{6}$ But they have something in common, something surprising: a belief that their Harvard colleague, John Rawls, is in line with their own views and with Wittgenstein's, and that he has roughly got ethics and political philosophy right.

This convergence of two otherwise crucially-divergent thinkers, to me, is a sign that something is awry. It is a sign of a far more general phenomenon: the over-determined wish of many academics and intellectuals to believe that Rawls's political philosophy is roughly right. Because the psychologically-gorgeous fact about Rawls is that he (apparently) powerfully enables one simultaneously to believe the following three attractive

${ }^{6}$ See for instance James Conant's piece in Philosophical Investigations, "On Wittgenstein" (2001), for the deep differences between their two approaches. 
(though surely in any case mutually-incompatible, on serious reflection) propositions: (1) To believe that one is being radical, leftist, even (allegedly) 'egalitarian'; (2) To believe that one can proudly uphold the values of liberalism and tolerance; and (3) To believe that, actually, hardly anything actually needs majorly changing in our world... As Stokely Carmichael held: The liberal wants to radically reform the world and make it better - so long as such reforms do not contain any risk of resulting in any diminution of his own position of privilege...

In a justly-famous paper, "On Rawls and political liberalism", 7 Burt Dreben argued that Rawls's mature political philosophy is compatible with Wittgenstein (and is right). Dreben was always a Rawlsian (and arguably vice versa, too), and so this isn't that surprising. But Cavell's case is more interesting:

Cavell, from a very different starting point (he is keen purportedly on some kind of perfectionism, and favours a 'dialogical' and highly nonscientifical vision of Wittgenstein that was often at odds with Dreben and that would at first blush seem less akin to Rawls) argues much the same in the Preface of his 'Conditions handsome and unhandsome' ${ }^{8}$ (Cavell is, in other words, very soft on Rawls, and surprisingly unwilling to put any clear water between himself and Rawls; he ends up only insignificantly differing from any standard Rawlsian liberal.).

Cavell emphasises an interesting term, the 'conversation of justice'. There is a danger lurking here (to which I will return in the section called "Contractarianism and the anti-'private-language' considerations", below), of buying into the contract-fiction as if it were something like fact. And of restricting the 'reach' of true justice only to those who can converse. 9

${ }^{7}$ See especially the opening paragraph of this paper of Dreben's.

${ }^{8}$ Page numbers in the body of the text. Is there a clear-sighted glimpse in Cavell of the liberal apologia for inequality (injustice?) in Rawls, at p.108 of his text?: "We know what the original position has prepared us for, what the liberal veil has disclosed: the scene of our lives. The public circumstances in which I live, in which I participate and from which I profit, are ones I consent to. They are ones with an uncertain measure of injustice, of inequalities of liberty and of goods that are not minimal, of delays in reform that are not inevitable."

${ }^{9}$ As suggested below: this is especially dangerous in that it removes future generations from (the conversation of) justice. 
Let us consider some of the key moments in Cavell's quasiendorsement of Rawls:

"If I am right that the project of Emersonian perfectionism demands no privileged share of liberty and of the basic goods, Rawlsian justice should hold no brief against it." (xxii)

"To prove that at any time within the circumstances of justice...there is an optimal resolution to [the conversation of justice] (a set of principles whose choice will receive optimal agreement) is one of Rawls's notable achievements." (xxv)

"[I am] speaking of Perfectionism not as a competing moral theory (say requiring a principle of justice or ordering of principles different from the proposals of Rawls) but as emphasizing a dimension of the moral life any theory of it may wish to accommodate." (xxxi)

"[When] perfectionists find their lives to be without justification (perhaps explicitly because they would be ashamed to argue to those less advantaged that those others are without claim against those more advantaged that those others are without claim against those more advantaged and that nevertheless society continues to deserve their consent from below) that then what they show is their consent to their lives, hence consent from above to the society that makes both their lives and the other lives possible." (p.124). ${ }^{10}$

At various other points in the book, Cavell sounds somewhat as if he is going to seriously differ from Rawls, and defend Emerson. But his disagreement with Rawls turns out to be only on the claim (of Rawls's) that a rational plan of life is (of) a life that can be lived "without reproach". ${ }^{11} \mathrm{Cav}$ ell doesn't contest the architecture of the original position, he doesn't contest the difference principle, ${ }^{12}$ he doesn't contest the primacy of justice. ${ }^{13}$ Cavell is too keen for Rawls to be basically right.

${ }^{10}$ I am not certain that I understand Cavell's meaning here, but it certainly seems an outright endorsement of elitism as well as inegalitarianism. (Cf. also p.103, p.108). This is very disappointing, given the apparent clarity of the parenthesis about what the fundamental problem with the difference principle surely is.

${ }^{11}$ I return in the section on "Honesty", below to just how strong a way into what is wrong with Rawls this idea contains the germ of.

12 Contested in my "Three strikes against the difference principle", forthcoming.

${ }^{13}$ Contested in my "How ought to think of our relationship to future generations?", forthcoming, and also in the section of the present paper immediately following 


\section{Is justice the first virtue of social institutions?}

My view is that both Cavell and Dreben are wrong. Rawls is a profoundly un-Wittgensteinian thinker (and is not right). Rawls was influenced to some extent by (his other key Harvard colleagues) Quine and Goodman, but not in any meaningful way by Wittgenstein. For example:

- This is intimated from the outset, in his title 'A Theory of Justice'. For a Wittgensteinian, pushing a theory in philosophy is bound to be suspect. The only way that Rawls's approach, of developing a theory of justice, can I think be defended as Wittgensteinian is by positing this theory as merely an 'object of comparison' (to use Wittgenstein's term) by means of which we are assisted in our quest to attain 'reflective equilibrium' (to use Rawls's term). But this defence is implausible: e.g. Because if one is constructing merely an object of comparison, one does not need to go into the kind of extreme detail that Rawls goes into.

- Rawls moreover provides a justification for the exploitation of persons ${ }^{14}$ and for the exploitation of the Earth by all, harnessing the power of science (and of 'social science') in order to do so. This too would have been anathema to Wittgenstein, who was deeply concerned that scientism was debasing our civilisation.

But I shan't push or try to develop these two points here. They would need sustained argument that I cannot give space for here, and might take us into unfertile debates about the nature of philosophy or about the nature and limits of scientism or about civilisation, 'progress', and pessimism ${ }^{15}$. I don't for instance want to get bogged down into a tedious rehash of questions over the place if any of 'theory' in philosophy.

Instead, I want to highlight the more certainly anti-Wittgensteinian aspect of Rawlsianism in its initial assumption (stated in the famous opening sentences of 'A theory of justice') that "Justice is the first virtue of so-

this one. (Nor does Cavell contest the opening sentences of $A$ theory of justice, considered in "Is justice the first virtue of social institutions?", below.)

${ }^{14}$ See my "Is the difference principle exploitative of persons?", forthcoming, jointauthored with Phil Hutchinson.

15 See my "Wittgenstein and greens on "progress", forthcoming. 
cial institutions. A theory however elegant and economical must be rejected or revised if it is untrue; likewise laws and institutions no matter how efficient and well-arranged must be reformed or abolished if they are unjust". (ToJ p.3) I want to contest the founding Rawlsian assumption, of the primacy of justice.

Assuming that "Justice is the first virtue of social institutions" would I believe have been anathema to Wittgenstein. Alternative possibilities ${ }^{16}$ deserve serious consideration: e.g. That care, love, or the fostering of love and care, is the first virtue of social institutions. These possibilities may seem utopian: But if it is true (as I believe to be the case) that a society that seeks above all to provide justice, where that 'justice' is in fact largely a coded apologia for the status quo, and where the status quo is long-term profoundly unsustainable, is doomed, then the only realistic thing to do is to seek - to demand - the allegedly-utopian. ${ }^{17}$

The second sentence of this quote from Rawls at first blush seems completely unobjectionable. How could anyone deny that "A theory however elegant and economical must be rejected or revised if it is untrue; likewise laws and institutions no matter how efficient and well-arranged must be reformed or abolished if they are unjust"? And Rawls wants the claim to seem natural, unobjectionable, to pass without sustained attention. But for a Wittgensteinian, it is cases such as this that are exactly what real philosophy is for: To unravel the trick that biased the pitch before we even noticed that the game had begun.

I don't like the unquestioned scientistic-looking analogy in the second sentence here. But as I say, I am not going to rely on that worry of mine. What is more deeply troubling is what it leads Rawls to do (or more precisely: not to do): namely, to fail to consider seriously alternative possibilities as candidates for being the first virtue of social institutions. ${ }^{18}$

${ }^{16}$ Here I am thinking especially of the later Gordon Baker's reading of Wittgenstein.

${ }^{17}$ On p.106, Cavell rightly points out that Rawls himself is a utopian thinker in $A$ theory of justice. It is this point of course which has prompted Sen's recent magisterial response to Rawls, The idea of justice (2009). My point is that Rawls is, by contrast, not utopian enough.

${ }^{18}$ For development of this theme, see again my "How ought to think of our relationship to future generations?", forthcoming. 
There is of course some consideration of perfectionism etc in Rawls's text. And of utilitarianism. But there is no explicit or serious reconsideration of the claim begun with (It is not even really recognised as a claim)... e.g. in the light of possible questions about how good or how important fairness really is; or how complete in its reach it is. Possible questions about whether fairness can for example take seriously the interests of those who cannot converse with us.

Is justice the first virtue of social institutions? My claim is that Rawls has biased the pitch, by assuming that justice trumps the rest. $\mathrm{He}$ makes it by fiat impossible to ask the deep questions which could undermine liberal political philosophy. The conjuring trick is made at the outset, and it was the very move that appeared entirely innocent. ${ }^{19}$

\section{Contractarianism and the anti-'private-language' considerations}

Central to Rawls's project is the idea, that he is quite explicit about as a kind of claim: that his is a contractarianism for our times. But contractarianism has a familiar problem: How are we to understand a non-actual contract?

Let me take an important for-instance of this. I have already touched on my suspicion that assuming justice to be the first virtue of social institutions creates real difficulties in taking seriously the claims of those with whom we cannot have a conversation, and to whom fairness therefore is likely to be an inadequate attitude: for instance, animals, the very ill, the very young, the very disabled, and the unborn. The latter, in totality, is probably the most important category: for it includes all future generations.

So far, so familiar: as I say, this is a familiar problem with contractarianism. But it ought to make Wittgensteinians especially wary thereof. For there lurks hereabouts a real risk of descending into a mire of nonsense.

What do I have in mind? Let me explain, by dwelling briefly on a case where this problem is particularly stark, namely, the case just alluded to: the political and ethical place of future generations in the design of our

${ }^{19}$ Cf. PI 308. 
social institutions. An absolutely fundamental question for political philosophy.

Rawls's approach to the question of future generations is to admit that it cannot be straightforwardly included within his contract schema. Instead, he introduces his 'just savings' principle, a principle that can be (very crudely and very approximately) understood as a kind of intergenerational analogue to the difference principle. Enough must be saved to allow the next generation to be at least as prosperous as this one.

This principle is extremely closely analogous to the principle of 'sustainable development' that has dominated international institutions' thinking about the $3^{\text {rd }}$ world and about future generations for the last generation, ever since the Brundtland Report. But it is extraordinarily vulnerable to the central problem with contractarianism: that there is no real contract. Rather, you fantasise a contract...

The worry is that if we are allowed to fantasise a contract, we are almost bound to drift into bad faith. With contractarianism which centres upon the current generation, this difficulty is not necessarily disastrous: for, actually-existing people who can answer back function as a kind of reality check upon any imagined contract. With regard to future people, there is no such check.

Compare here sections 243-282 of Wittgenstein's Philosophical Investigations... The absence of a real contract and the presence of a through-and-through fantasised 'contract' in a situation (i.e. our relations with future people) where there could not possibly be a contract (in part because our decisions will partly decide which future people there are! ${ }^{20}$ ) is roughly analogous to Wittgenstein's questioning in this celebrated central body of the anti-'private-language' considerations of the through-andthrough fantasised 'language' under consideration there. In the end a 'language' through-and-through of one's own is no language at all; similarly, a contract with the future which in the end is only a contract with ourselves is no contract at all. Thus one can I think deploy Wittgenstein's considerations here against the concept of 'sustainable development', against

${ }^{20}$ Compare here Wittgenstein's oft-repeated nonsense-riddle, "What time is it on the Sun?" The Sun determines our time calculations... 
closely-parallel alleged principles of justice such as Rawls's 'just savings', and in fact against any application of Rawlsian thinking to the future.

A 'contract' which surely is not and could not possibly be a contract... Are you really happy using the word 'contract' here at all, still? This is the question that Wittgenstein asks of his unwary reader again and again, as he plunges that reader again and again into the waters of doubt: Are you really happy to call this language? And this? And that? (And even: is there any this there?) A pretence of language when one will oneself on reflection feel that there is none: this is the worry that Wittgenstein raises I think for the concept of Rawlsian 'contractarianism' ${ }^{21}$ (and for the way we fool ourselves with analogous reassuring ideas such as 'sustainable development' ${ }^{22}$ ).

The very idea of a 'private language' is absurd, nothing. Similarly, the 'contract' of Rawls and his predecessors is a contract with nobody, a contract 'private' to its purveyors. There is no real contract, and there could not possibly be a contract with future people.

Now, Rawls's backers might here stress the fact that Rawls doesn't reply on strictly contractarian thinking to help decide how we ought to treat future people. He treats them, rather as a kind of special case, and (as mentioned above) puts forward his 'just savings' principle to decide on their treatment (See section 44 of ToJ.) But to me, this makes things if anything even worse. Because it is ludicrous to pretend that future generations are a special case, something to consider secondarily. This is another disastrous consequence of treating justice as the first virtue of social institutions: it inclines us to think of people contemporaneous with one another and able to contract with each other as our paradigm case for political philosophy. Whereas, any political philosophy that fails to place centrally our responsibility for the future is condemnable, it seems to me, grossly derelict in its duty.

Rawls is held captive by an interlinked set of pictures: of people as at base individuals, juridical subjects; of social institutions as (like) law; of political philosophy as (like) science. All these three pictures, for Wittgen-

\footnotetext{
${ }^{21}$ I am thinking here for instance of the closing sentences of PI 258.

${ }^{22}$ See John Foster's The sustainability mirage (2008).
} 
steinians, are (a) ungrounded, (b) in dire need of being challenged by alternative pictures, and/or (c) if not so challenged, then anathema. ${ }^{23}$

\section{Honesty: the first virtue of philosophy}

These considerations above can be brought together under the heading of a reflection on the degree to which these two thinkers, Rawls and Wittgenstein, were intellectually honest.

Wittgenstein was overwhelmingly concerned with the intellectual virtue of honesty, especially honesty with oneself. I believe that he would see in Rawls a philosophy that for each of us entertaining it courts dishonesty, projected to recommend a society that would be systematically dishonest with itself.

Cavell says the following, at the beginning of Conditions handsome and unhandsome:

"What I have to say...in these lectures builds from my sense of rightness and relief in Rawls's having articulated a concept of justice accounting for the intuition that a democracy must know itself to maintain a state of (because human, imperfect, but), let me say, good enough justice." (3) I am denying this. Though - indeed, because - I profoundly agree with the injunction to democracy: Know thyself. I think that a democracy that cannot know itself cannot really be a democracy. The people do not rule if they do not know their own principles and practice.

I hold that Rawls's is a political philosophy only well-suited to a society that is in the final analysis relatively unworried about the 'congruence' of its principles. "Congruence" is Rawls's term for the self-transparency and self-acceptability to a society of a set of principles of justice. It is, one might say, honesty writ large. Honesty gone fully public.

${ }^{23}$ The point might also be put in this way. The concept of agreement involved in Wittgenstein's idea of 'agreement in opinions' (see PI 240-2) is basically the ordinary concept of agreement. Agreement to make (say) a real contract. But by hypothesis there is no real contract, in contractarianism. The hypothetical contract: can it be compared to (what Wittgenstein calls) agreement in judgements? In form of life? Well: not very easily. For where such agreement is not present then it is not present, and one cannot pretend one's way around that. Agreement over fairness is not like agreement over colour-concepts. It is dangerously mythical to pretend otherwise. 
I hold this because the 'difference principle' is not even genuinely action-guiding (and thus, ironically, is no better than the Utilitarianism it was specifically-designed to better): it can be used to justify any level of inequality whatsoever, if one makes rigid enough assumptions about the level of incentives required to motivate the rich, and loose enough assumptions about the plasticity of mind of the poor. ${ }^{24}$ Just insofar as a Rawlsian society thought itself egalitarian while promoting inequality via the difference principle, and/or thought itself Pollyanna-ishly indefinitely able to be sustained and 'develop' into the future while taking a 'fair share' of what the future may very well turn out desperately to need ... so far Rawlsianism is not honest, not 'congruent'. Just insofar as Rawls says to the poor "Though shalt not envy the rich", or to the future "Be unreproachful of us for what we have done which was in your best interest - Honest!"...

And I believe that Cavell's own text actually does supply the resource that can enable us to recognise a key element of this:

"If there is a perfectionism not only compatible with democracy but necessary to it, it lies not in excusing democracy for its inevitable failures, or looking to rise above them, but in teaching how to respond to those failures, and to one's compromise by them, otherwise than by excuse or withdrawal. To teach this is an essential task in Rawls's criticism of democracy from within. My sense of affinity, yet within it an unease, with A Theory of Justice, turns on the content of this teaching, epitomized by Rawls's injunction to the democrat to find a way of life that is "above reproach" ( $T o J$ p.422). My unease here is roughly the sense that looking for such a life is not enough to contain the sense of compromise done to my life by the society to which I give my consent (I assume that living "above reproach" is meant to do this, and that the life looked for is not like the one Thoreau found.)." (p.18; cf. also p.113).

Rawls does indeed want us to feel above reproach in what we do for the poor, what we do for the future ones, etc.: "we have the guiding principle that a rational individual is always to act so that he need never blame himself no matter how things finally transpire." (ToJ p.422). Being a Rawlsian liberal means never having to say you're sorry... My suggestion has been that liberals' striving to be 'above reproach' results in a fundamental dis-

${ }^{24}$ For detailed argument to this conclusion, see my "The difference principle is not action-guiding", forthcoming. 
honesty: because we nevertheless don't do enough to create a decent, congruent society that can be sustained.

Honesty is the first virtue of intellectuals. It is that without which.

It is an essential element in the moral life, and the essential precondition of intellectual life.

Wittgenstein urged upon one the ceaseless practice of honesty, including the practice of owning up to and allowing to consciousness all one's desires, so that one could work on them and in many cases overcome them. Wittgenstein thereby pursued in himself and urged upon his reader a highly perfectionist (and therapeutic) version of philosophising. Here is a lovely remark of Cavell's from Conditions handsome and unhandsome, about this: "I think Philosophical Investigations may be seen not as a repudiation of [the Tractatus], but as a further way of responding to the, let's say, absolute responsibility of the self to itself [starkly laid out in the Tractatus]... Call this the absolute responsibility of the self to make itself intelligible, without falsifying itself." (xxvii).

What is Rawls's raison-d'etre? To pull off the mind-bending propaganda coup of getting people to think that one can be an egalitarian, as left as is respectable in a democracy, while building inequality into the basic structure of society. The trick of getting the rich to think that it is in everybody's interest for them to be rich, and of getting the poor to think that their envy of the rich is irrational and that they ought to think their way out of it. And all this, in the name of reflection! ('Reflective equilibrium') What could be more self-falsifying...

Compare now Jerry Cohen's beautifully-entitled book, If you're an egalitarian, how come you're so rich? I call the motivation of Rawls's philosophy self-deceiving, and the society that he envisaged basically dishonesty - dishonest at the base, from the roots up. Just plain uncongruent.

And more so than ever, in an age wherein humanity has reached the limits to growth, as people perhaps first became painfully aware that we as a species were doing in the very decade during which Rawls wrote $A$ theory of justice. Rawls's Minervan owl had flown before the ink was even dry on his pages. Because, at the limits to growth, you can't keep 'efficiently' taking from the Earth to sustain growth and inequality and thus drag up the hindmost. And you have instead, if you foster a competitive 
society, to face a kind of zero-sum game for resources, in which everyone doesn't gain in the way claimed for by the difference principle.

Compare the following important moment in Rawls's text, in the infamous section of Theory of Justice on "Envy and equality". Here, Rawls is trying to draw the sting from the claim that envy can be justified and undermines the difference principle:

"Suppose first that envy is held to be pervasive in poor peasant societies. The reason for this, it may be suggested, is the general belief that the aggregate of social wealth is more or less fixed, so that one person's gain is another's loss. The social system is regarded, it might be said, as a conventionally established and unchangeable zero-sum game. Now actually, if this belief were widespread and the stock of goods were generally thought to be given, then a strict opposition of interests would be assumed to obtain. In this case, it would be correct to think that justice requires equal shares [i.e. true equality, not difference-principle-style-'equality']. Social wealth is not viewed as the outcome of mutually advantageous cooperation and so there is no fair basis for an unequal division of advantages. What is said to be envy may in fact be resentment which might or might not prove to be justified." (ToJ, 539; italics mine)

The situation envisaged here is (roughly) our collective situation, as a species. This is a rough picture of our shared world, our finite world. A world in which a possible zero-sum-game can be turned into a scheme of genuine co-operation, as it must be, only through the kind of uncompromisingly uncompetitive and genuinely egalitarian thinking found for example in World War Two Britain (with the rationing system, etc), or in stone-age economies - or in some peasant societies - writ large. ${ }^{25}$

Whatever was left standing in Rawls of the difference principle before, the dire need for ecosystemic awareness and for respect of the limits to growth makes fall.

A second strand, I believe, of willed self-deception in Rawls and like-minded liberals concerns the absurd pose that it makes any sense to be neutral between conceptions of the good. Such 'neutrality' covertly fosters certain conceptions of the good - It covertly favours societies where more and more is privatised. It turns everything into a question of consumerism. It makes it impossible for many of one's deepest commitments to be considered anything other than one's 'interests'.

${ }^{25}$ For explication, see the work of Richard Wilkinson and Marshall Sahlins. 
I cannot hope to justify this claim in the present paper. But it does lead neatly into the final point I wish to make in this paper:

\section{The later Rawls: A more Wittgensteinian Rawls?}

Rawls did not, contrary to the beliefs/desires of many Wittgensteinians (most notably, Dreben, and Juliet Floyd, and of course Rorty) genuinely overcome his leanings toward scientism, theoryism and the hazards of contractarianism in any serious way in his later work. Rawls's later work is in a certain sense less theoreticistic, which is good; but it is more individualistic than his early work. It thus moves in exactly the wrong direction, if one believes that what will be needed to save us is a god, or a shared ethic of love or of care, or anything pointing in the opposite direction to consumeristic materialism and the taking of income and wealth as 'primary social goods'.

In brief (in the current context, I can only sketch my view on this matter, as this paper has primarily concentrated on $T o J$, not on Political Liberalism etc) ${ }^{26}$ : The later Rawls in fact generalises consumerism and individualism more than the early Rawls thought of doing: As a denizen of a pluralistic society, one is taken, in the later Rawls, to have what I call a consumeristic attitude towards religion, towards ethics, towards political theory, what Rawls calls 'comprehensive views', and thus even, in a way, towards philosophy itself. Rawls abandons any hope of society unifying around one such view or family of views. This is a vision of society gone irretrievably into fracture.

In such a scenario, there is less chance of adoption of a conception of the good that could conceivably trump or turn the tide of our devotion at the temple of materialism, the religion that is killing us and killing our collective home.

The later Rawls is an apologia for consumerism gone mad.

${ }^{26}$ A view developed in my "On Rawls's failure to preserve genuine (freedom of) religion", forthcoming; this paper is previewed in the part of my Philosophy for Life (2007) on 'Religion'. 


\section{Conclusion}

Many Wittgensteinians, especially a number of 'New Wittgensteinians' (philosophers very similar in outlook to myself) who pride ourselves on taking a rigorously 'therapeutic' approach to philosophy, have been seduced by Rawls (In my view, the likely reason for this is that given earlier: the immense psychical attractiveness of Rawls's supposed 'egalitarian liberalism' as at once confirming one's radicalism and removing from one the requirement to actually do anything to seriously change things). It is time that this wrong-headed love affair came to an end. To be a real Wittgensteinian, one has rigorously to probe the seductions and bewitchments to which one is prone - even if doing so has uncomfortable consequences in terms of the need to alter one's level of affluence and/or one's practical political commitments.

This suggests scope perhaps for developing the moral perfectionism of Cavell, but on egalitarian foundations rather than on the basis of Rawls's inegalitarianism. Building on Wittgenstein's honesty, developing a society-wide honesty and congruence incompatible with Rawlsian liberalism. Openly favouring some conceptions of the good over others (this will necessarily involve some conflict; honesty about that is necessary, too), and developing and fostering the virtues to / that favour those. Such a perfectionism would simultaneously face three ways: toward the self (making oneself morally as good as possible), toward others (caring for them, as for oneself; loving them - One is by definition not morally perfect if one cares too much about one's own moral perfection ${ }^{27}$ ), and toward the culture as a whole (making it one to be proud of and that genuinely improves, rather than declining because of what gets called, ironically, the march of 'progress'). Such a perfectionism, particularly in its emphasis on perfection being about genuinely doing one's best for and toward others naturally fits with egalitarianism. Including toward the future ones, ridding ourselves of the out-of-date self-serving illusion that they are likely to be richer than us. ${ }^{28}$ Loving them, and being the kind of person who does enough, ${ }^{29}$ who cares-and-loves-in-action, not just in theory.

\footnotetext{
27 This perhaps was a moral flaw in Wittgenstein the man.

${ }^{28}$ For development of this line of thought, see once again my "How ought to think of our relationship to future generations?", forthcoming.
} 
But one doesn't need to accept all of that, to accept at least this, that I hope to have shown here: that to be a Wittgensteinian is ipso facto to be at the very least in serious tension with Rawls, and not, as too many have had it, to be onside with him. And this lesson is hardly restricted to Rawls: for he is but the icon of liberal political philosophy, a massive and dominant tradition including other thinkers too, as diverse as Dworkin, recent Habermas, and even (in many respects) Sen or Stiglitz.

Wittgenstein's philosophy ought to make anyone who holds to it deeply suspicious of liberalism, in all its forms - and interested in looking for an alternative that might actually be liberating for us, intellectually and otherwise. $^{30}$

${ }^{29}$ Enough to ensure that we as a species win the 'climate war', for instance. As Winston Churchill once remarked: 'It's not enough that we do our best; sometimes we have to do what's required.'

${ }^{30}$ This paper was first presented at the Kirchberg Wittgenstein Symposium, August 2009. My thanks to those present there, and also to an audience at the University of Helsinki, for very helpful comments. 


\section{Literature}

Cavell, Stanley 1990: Conditions handsome and unhandsome. Chicago: U. Chicago Press.

Cohen, G.A. 2001: If you're an egalitarian, how come you're so rich? Cambridge MA: Harvard.

Conant, James 2001: “Contribution to 'On Wittgenstein"”. Philosophical Investigations 24(2), 89-184.

Crary, Alice / Read, Rupert (eds.) 2000: The New Wittgenstein. London: Routledge.

Dreben, Burton 2003: "On Rawls and political liberalism". In: Freeman, Samuel (ed.): The Cambridge Companion to Rawls. Cambridge: C.U.P., 316-346.

Foster, John 2008: The sustainability mirage. London: Earthscan.

Rawls, John 1971: A Theory of Justice. Oxford: OUP. (ToJ)

Read, Rupert 2007: Philosophy for Life. London: Continuum.

Sen, Amartya 2009: The Idea of Justice. New York: Allen Lane.

Wittgenstein, Ludwig 1993: “"Philosophy' from the Big Typescript”. In: Ludwig Wittgenstein: Philosophical Occasions. Indianapolis: Hackett.

Wittgenstein, Ludwig 1958/1953: Philosophical Investigations. London: MacMillan. $(P I)$ 